\title{
Cabildos de naturales en el ocaso colonial: jurisdicción, posesión y defensa del espacio étnico
}

\author{
ALCIRA DUEÑAS \\ Ohio State University, Newark \\ duenas.2@osu.edu
}

\section{RESUMEN}

Este ensayo examina ciertos cambios críticos en la jurisdicción de la «República de indios» en el Perú colonial tardio. Busca además problematizar el significado del concepto de "posesión» y del derecho de usufructo en el contexto de la propiedad comunal en los pueblos de indios y los cambios producidos en la jurisdicción indigena en 1777 con la creación de las subdelegaturas que reemplazaron el juzgado del corregidor. Las Ordenanzas de Intendencia de 1784 y 1803 desplazaron más certeramente la autoridad jurisdiccional del Cabildo indígena y su capacidad de decisión en cuanto al ordenamiento espacial del pueblo. Los procuradores y jueces del Cabildo de Chorrillos, entre otros, avanzaron una sistemática defensa legal de la propiedad comunal y un nuevo sentido de la etnicidad urbana. Al amanecer del siglo XIX, se profundizaba una refinada cultura letrada anclada en el potencial jurisdiccional de la «República de indios» con una larga tradición de escritura y lucha legal. Desafiando la autoridad del juez subdelegado, el Cabildo respondia tácitamente al proyecto borbón de control politico local de los pueblos, intentando rescatar los últimos vestigios de comunidad que permanecian aún en los pueblos del valle de Lima al final de la experiencia colonial.

Palabras clave: Autonomía de los Cabildos, propiedad comunal, derechos de posesión, Chorrillos, jurisdicción 


\section{ABSTRACT}

This essay examines important changes in the jurisdiction of the Republic of the Indians in late colonial Peru by problematizing the concept of possession and usufruct of communal lands in the Indian towns after 1777, when the Bourbon set the sub-delegate courts to replace the former court of the corregidor. The 1784 and 1803 Ordenanzas de Intendencia displaced more firmly the jurisdictional authority of the indigenous Cabildo and its ability to influence the organization of the town's spatial order. The indigenous Cabildos' legal advocates and judges waged in court a systematic defense of communal property and created a new sense of community in the urban setting. At the dawn of the nineteenth century, a rather sophisticated lettered culture anchored in the jurisdictional potential of the republic of the Indians and with a long tradition of legal struggles and legal writing revealed itself. Defying the legal authority of the sub-delegate, the council offered a tacit response to the Bourbon project of political control of the pueblos, in an effort to salvage the last vestiges of community that still remained in the Lima valley's towns at the end of the colonial experience.

Keywords: Cabildo autonomy, communal property, possession rights, Chorrillos, jurisdiction

$\mathrm{V}$ arias décadas después de fundadas las reducciones de indios — anteriores y posteriores al gobierno del virrey Francisco de Toledo-era ya claro que solo algunas devinieron en pueblos estables y aglutinados políticamente alrededor de sus cabildos. Aun así, estos pueblos y sus autoridades consiguieron un nuevo espacio jurisdiccional al interior mismo de la «República de indios», en ocasiones disputando la autoridad del cacique, quien hasta entonces representaba la única instancia de acción legal de tal «república». La jurisdicción del Cabildo de naturales no estaba claramente demarcada territorial y judicialmente con respecto a la jurisdicción del cacicazgo, y con frecuencia su competencia y la de los corregidores fueron objeto de disputas. Sin embargo, en algunos pueblos el Cabildo disfrutó de relativa autonomía para mediar consuetudinariamente en la adjudicación de tierras de comunidad, conducir ceremonias de posesión, dirimir conflictos de tierras en los confines del pueblo e 
intervenir en asuntos de justicia civil que involucraban indios del pueblo y cuantías de dinero menores de treinta pesos de plata corriente. ${ }^{1}$ Pero la consolidación del sistema colonial, y particularmente la reconstitución del imperio español después de las reformas borbónicas, alterarán significativamente la visión toledana de los pueblos.

Este ensayo versa sobre algunos cambios ocurridos en el ámbito jurisdiccional de la «República de indios» y busca problematizar el significado del concepto de "posesión" y del derecho de usufructo en el contexto de los cambios operados en la propiedad comunal de las tierras distribuidas por el Cabildo de naturales a los residentes del pueblo de San Pedro de Chorrillos durante los últimos años del dominio colonial. Sugiero que, con el avance de las relaciones coloniales, el estatus de la propiedad comunal en los pueblos de indios del valle de Lima, y el derecho de usufructo aparejado a ella, sufrió una creciente transgresión desde dentro y fuera del mundo indígena. Tal proceso puso en jaque el sentido de autonomía local del Cabildo de naturales. Así, las disputas del derecho de posesión y el usufructo llevadas a las cortes americanas, en particular, y el ímpetu Borbón por el control político a nivel local después de 1777, de modo más general, representaron para el Cabildo indígena la pérdida casi completa de su jurisdicción en la adjudicación de solares, parte importante de su autonomía local y su poder de influencia en el ordenamiento social del pueblo.

Ante esta realidad el Cabildo respondió con una sistemática defensa legal de la propiedad comunal —el derecho de los miembros del pueblo a la posesión y usufructo- - y la condena abierta a las prácticas cada vez más frecuentes de apropiación individual de las tierras de la comunidad

1 Si bien Toledo estableció estos términos en sus Ordenanzas, al igual que el carácter sumarial de los juicios civiles locales, eso no significa que los cabildos no produjeron un nutrido registro documental. La variada producción notarial y los registros de justicia civil como los pleitos por distribución de «tierras de repartimiento», las ceremonias de posesión, los juicios sobre aguas, entre otros, son la materialización misma del archivo colonial indígena que reposaba dentro y fuera de las casas de cabildo. Actualmente estoy desarrollando estos aspectos en el marco de los pueblos de indios y la construcción del archivo colonial indígena en un proyecto más amplio de investigación. Para el valle de Lima, numerosos registros están disponibles desde la segunda mitad del siglo XVII y, en mucha menos cuantía, para años anteriores. 
y sus recursos productivos por parte de españoles y también por indios originarios y forasteros. Este ejercicio del recurso legal como mecanismo de reconstitución del espacio étnico urbano seriamente amenazado, al amanecer del siglo XIX, puso en evidencia la maduración de una refinada cultura letrada que emanaba del Cabildo de naturales. Esta cultura legal, surgida siglos atrás en la región, estuvo sustentada en una mayor especialización de las funciones del Cabildo, el conocimiento detallado de los procedimientos legales, la nueva legislación borbónica de 1784, y en un importante saber local que permitió desafiar las acciones tanto de agentes usurpadores como del juez subdelegado. Así, se delineó un discurso técnico-legal especializado, articulado por el procurador del Cabildo, cuya voz lideró la defensa en general del pueblo de indios y sus recursos justo en el tiempo de su aparente decadencia.

$\mathrm{El}$ archivo indígena colonial contiene un volumen importante de registros que documentan la práctica consuetudinaria edilicia de distribución de solares, ofreciendo una valiosa aproximación al micromundo de la cultura legal creada por el Cabildo indígena en los pueblos, tema de mis otras investigaciones actuales. Los documentos resultantes de esta práctica registran sus aspectos básicos, tales como el reporte de la petición, las pertinentes inspecciones rituales de orden legal llevadas a cabo por el Cabildo y las ceremonias de posesión propiamente dichas que sancionaban el derecho de los indios residentes a la posesión del solar. Estos registros documentales, sin embargo, ocultan los conflictos intracomunitarios latentes tras los rituales legales que sancionaban la posesión en los pueblos de indios (vistas de ojos, demarcación y medición de linderos o "deslindes"). Revisando cuidadosamente tanto los documentos de tierras de comunidades del valle de Lima como aquellos generados en la corte del juez subdelegado se pueden detectar conflictos al interior y entre las comunidades indígenas sobre la posesión de los solares, en el crepúsculo colonial, que eventualmente se dirimieron fuera de la jurisdicción edilicia, debilitando el poder de sus cabildos para incidir y retener el carácter indígena de la población local. 
POBLANDO EL PUEBLO: POSESIÓN Y USUFRUCTO EN LA ESCENA COLONIAL

Más que el título de propiedad per se, era la posesión de la tierra el elemento definitorio de la relación de propiedad en el contexto legal ibérico del llamado «antiguo régimen». En el sentido más lato del término, «posesión» significaba el uso demostrable de la tierra, ya fuera mediante el cultivo o el pastoreo. En el contexto de las municipalidades, el abandono de la misma indicaba que el poseedor ya no la deseaba para su uso y, por tanto, la tierra quedaba disponible para que otro tomara la posesión; el anterior poseedor quedaba impedido de elevar reclamo alguno. ${ }^{2}$ El concepto de posesión y la noción de usufructo viajaron a América de la mano de las relaciones coloniales, permeando el universo de relaciones sociales en las reducciones y los pueblos de indios que perduraron tras las fundaciones iniciales. La propiedad sobre los bienes llamados «propios», tanto en las ciudades y pueblos españoles como en los pueblos de indios, era de carácter comunal y corporativo; es decir, los manejaba el Cabildo para la generación de recursos orientados a financiar los gastos de la Municipalidad.

Es importante subrayar aquí las aparentes similitudes entre esta noción europea de propiedad común y los modos colectivos ancestrales de acceso a la tierra y al producto del trabajo que pudieron haber informado la tenencia de la tierra y las relaciones sociales en los sistemas preincas, incas y en otras comunidades andinas en el tiempo anterior a la invasión española. ${ }^{3}$ Cabría pensar que tales similitudes formales, si

2 Vassberg 1974: 384. De no quedar demostrada la posesión no había lugar al derecho de propiedad o a la validez de tal título si existiera.

3 Susan E. Ramírez sostiene que dos sistemas diferentes de tenencia de la tierra coexistieron en el Perú colonial hasta la década de 1570: un «native system of repartimiento land" y un sistema de propiedad privada europeo. Seleccionando casos de la costa norte y algunos otros de las alturas andinas del Perú en el siglo XVI y el temprano XVII, la autora sugiere que tal sistema indígena de tierras de repartimiento fue eventualmente desplazado por el concepto de propiedad privada europeo, instigado por los programas de reducción, por el avance de la agricultura comercial a medida que nuevos inmigrantes espańoles arribaban al Perú, y por la adopción del sentido de propiedad privada sobre tierras de la comunidad por parte de los caciques (Ramírez 1996: 45 y 72). El uso de "posesión» en los testimonios indígenas citados por Ramírez, a mi entender, revela la intervención del protector de naturales español o de los abogados espańoles en los pleitos, 
bien incorporadas a formaciones culturales diferentes, pudieron facilitar la adopción de esta importación europea de la propiedad comunal y el derecho de usufructo durante la formación de los pueblos de indios. A partir de su fundación colonial, estos últimos recibieron "concesiones» reales de «tierras de comunidad" para ser asignadas a los residentes «originarios» con derecho al usufructo ya fuera como espacio de residencia o para beneficiarse de los productos allí cultivados, o para ambos fines. ${ }^{4}$ En el ámbito jurídico imperial castellano en cuanto al tema de la propiedad de la tierra, la premisa de fondo era que el rey soberanamente ejercía el dominiun sobre todas las tierras y los recursos productivos del reino, como propiedad pública. Así, ejerciendo su potestad, los otorgaba como merced o concesión a las repúblicas corporativas de sus súbditos. A cambio, el rey esperaba lealtad y la aceptación por parte de aquellos de su condición de vasallos, usualmente entendida como la obligación del tributo y la adopción del cristianismo, y su completa sujeción al control político imperial. ${ }^{5}$ En el Perú, los programas de reducciones llevaron a la creación de pueblos de indios en tierras que, antes que al rey de Espańa, correspondían al acerbo territorial indígena precolonial. A partir del siglo XVI, la condición colonial residiría entonces en hacer que el acceso a las tierras por parte de los indios recién asentados en pueblos se diera a través del marco legal español de "protección» y como un derecho al «usufructo» de tierras, no a la propiedad. Los indios recibían tales asignaciones reales solo en las cantidades que las autoridades coloniales consideraban necesarias para la subsistencia individual de cada familia. ${ }^{6}$

pero es insuficiente para sustentar la existencia del concepto de posesión en el ámbito prehispánico, especialmente si tenemos en cuenta que la posesión es consustancial al derecho de propiedad privada, al menos en el caso español.

4 Vassberg 1974: 389.

5 Tamar Herzog sostiene que los programas de reducción en América, antes que una política colonial orientada a controlar solamente a los indios, fue una política real general que buscaba incorporar indistintamente a los súbditos del rey bajo su control político y hacer que todos fueran efectivamente hispanizados, tal como lo fue en España la propia política de «repoblaciones» de gitanos y otros espańoles iniciada a fines del siglo XV (Herzog 2007). ${ }^{6}$ Como norma general los pueblos de indios solo podían extenderse dentro del radio de una legua medida a partir de la iglesia. La partición de las tierras en forma de solares 
Pero este sistema no era nuevo. Ya le era familiar a la población musulmana residente en la Castilla de la Reconquista, donde el rey había agenciado la «repoblación» de musulmanes y de sus tierras, ahora consideradas tierras de los monarcas castellanos. ${ }^{7}$ En tanto propiedad corporativa, las tierras de comunidad teóricamente no podían ser compradas o vendidas. Lo mismo sucedía con los solares en los predios del pueblo, pero estos eran asignados individualmente como una transferencia temporal del derecho de usufructo al residente y su familia.

En el mundo colonial americano del siglo XVI, el propósito de la transferencia era consolidar el poblamiento de las reducciones incentivando a los indios con la posibilidad de usar un espacio donde construir una casa y plantar una huerta familiar. ${ }^{8}$ El usufructo y la posesión de tal espacio se transmitían por línea directa de parentesco a los descendientes del beneficiario original hasta que el último miembro de la familia que recibiera la posesión hubiese muerto sin dejar un sucesor adulto conocido. En tal eventualidad, el solar revertía al Cabildo, como representante local de la autoridad real, para ser asignado a un nuevo solicitante. Así, las tierras usadas como solares operaban supuestamente al margen del mercado de tierras y los residentes del pueblo solo accedían a su uso o usufructo por mediación del Cabildo. El derecho al usufructo estaba usualmente garantizado por medio de un «mandamiento de amparo» que protegía al beneficiario original y sus sucesores en su derecho

individuales y la responsabilidad individual por la posesión y usufructo de los mismos difieren del uso colectivo y libre acceso a la tierra en tiempos anteriores a la llegada de Pizarro al Perú. Añádase al nuevo carácter colonial del acceso de los indios a las tierras el que, como en los casos de San Pedro de Chorrillos aquí analizados, tal acceso estaría intermediado por leyes que introdujeron nuevas nociones europeas como la «posesión», por un sistema de representación legal de manufactura española y por un sistema de escritura alfabética y comunicación en espańol, la lengua del colonizador. Para una explicación del proceso legal detrás de la desposesión real de los indios o para discernir cómo el sistema legal introducido después de la conquista sofisticadamente construyó una idea propia de los derechos de los indios a la tierra para 'reconocer' sus derechos, véase Herzog 2013. 7 Vassberg 1974: 384.

8 Ordenanza xxxvi, «Que las chacras vacas se den a los indios que no las tuvieren», y Ordenanza xxxvii, «Cómo se han de repartir y recompensar las tierras cuando los indios se pasan de unos pueblos a otros» (Ballesteros 1752: 133-134). 
de usufructo. Los registros documentales existentes de los pueblos de indios del valle de Lima, para la segunda mitad del siglo XVII y la mayor parte del siglo XVIII, sugieren que la distribución de las tierras en solares para los habitantes indígenas de los pueblos del valle de Lima fue llevada a cabo por parte del Cabildo indígena de cada pueblo de manera autónoma.

Pero la propiedad común en el pueblo sufrió, desde fuera, el avance arrasador de la propiedad privada por parte de forasteros espańoles, criollos y mestizos, aumentando la presión demográfica migratoria sobre los pueblos. Desde dentro, el impacto de prácticas de propiedad individual internalizadas por los mismos indígenas también erosionó la propiedad comunal. Aunque tales cambios ya se insinuaban desde el siglo XVI, hacia la década de 1650, las autoridades indígenas parecían saber bien cuáles eran las implicaciones del derecho español de la propiedad privada individual en cuanto al acceso a la tierra para las comunidades indígenas. ${ }^{9}$ Durante los siglos XVIII y XIX, su ímpetu era ya imposible de ignorar, como se demuestra en las secciones siguientes.

\section{LAS REFORMAS DE CARLOS III Y LOS PUEBLOS DE INDIOS EN EL VALLE DE LIMA}

Dentro y fuera de los pueblos de indios, el orden social indígena en el Perú del tardío siglo XVIII sufrió serias alteraciones por la acción combinada de la política borbónica de inflación tributaria, la formalización legal de la práctica abusiva de los repartos y, ante todo, la ineficacia del sistema de justicia para los indios, fundamentalmente en manos de corregidores seriamente comprometidos con los excesos que requerían pronta reparación. Entre otras, una de las principales aspiraciones de la insurrección general liderada por Túpac Amaru II y Julián Apasa, Túpak Katari, entre 1780 y 1783, se centraba en la restauración de la justicia para los indios debido a la negligencia, «abusos y vejaciones» perpetrados por los corregidores. Al proponer su reemplazo por un alcalde mayor de la nación índica y al demandar la creación de una nueva Real Audiencia 
en Cuzco, Túpac Amaru II expresaba la crisis del colonialismo español y su discurso de justicia. ${ }^{10}$ La rebelión sacudió las anquilosadas bases del sistema colonial español en los Andes y desencadenó una ola de miedo entre sus élites, todo lo cual es ampliamente conocido en la historiografía andina. ${ }^{11}$ Ante la inminente pérdida del control político de la «República de indios», el rey Carlos III respondió con premura creando las salvaguardas que creyó necesarias para asegurar la estructura vertical de la autoridad real de arriba a abajo. También quiso recuperar el sentido de la justicia y el control del orden público que le pudiera ofrecer seguridad y estabilidad a su más amplio propósito de incrementar el flujo de riqueza de los territorios de ultramar hacia la metrópoli.

Poco se ha estudiado el impacto de estas reformas en el nivel local de la «República de indios», un campo fértil de futuras investigaciones que puedan discernir las modificaciones experimentadas por la autoridad indígena en los cabildos y las relaciones sociales a nivel de los pueblos de indios como resultado de las reformas de Carlos III. En contraste, las autoridades del Cabildo a fines del período colonial sí estaban muy conscientes de estas reformas. De hecho, los procuradores del pueblo de San Pedro de Chorrillos, en la base documental de este ensayo, se refieren en distintas ocasiones a la «nueva ley municipal» o al «nuevo código de intendencia» para referirse a los instrumentos legales vigentes en los primeros años del siglo XIX en lo relacionado con la distribución de tierras en el pueblo. ${ }^{12}$

La respuesta de Carlos III al desafío de autoridad que representaron las rebeliones que pusieron en peligro las reformas fiscales y de comercio ya establecidas fue la emisión de las Reales Ordenanzas de Intendencia (1784), ${ }^{13}$ identificadas por los procuradores indios de Chorrillos en sus alegatos como «Código de Intendencia». Dichas ordenanzas

${ }^{10}$ Dueñas 2010: 78-86.

${ }^{11}$ Véanse, entre otros estudios pertinentes, Serulnikov 2003; Thomson 2002; y O'Phelan 2012.

${ }^{12}$ Archivo General de la Nación [en adelante AGN], Lima, Fácticas, CSC, L5, C137, 1813-1821, ff. 1-81v; AGN, Lima, Fácticas, CSC, L2, C42, ff. 47-48v.

${ }^{13}$ Ordenanza General 1803: 105. 
instrumentalizaron legalmente el esfuerzo centralizador y económico de los borbones en Hispanoamérica en el siglo XVIII tardío. En el virreinato del Perú, las Ordenanzas de Intendencia, entre otras reformas en los ramos de Real Hacienda, Guerra y Justicia, redistribuyeron el territorio creando intendencias y dieron amplia autoridad a los nuevos intendentes para la recuperación eficaz del control político y la promoción de los ingresos de la monarquía borbónica a nivel de su jurisdicción. ${ }^{14}$

Las intendencias fueron a su vez subdividas en partidos aproximadamente equivalentes a la jurisdicción de las antiguas provincias o corregimientos. El artículo 9 de las Ordenanzas de Intendencia, tal vez el más pertinente al propósito de este ensayo, reemplazaba a los antiguos corregidores y alcaldes mayores en las cabezas de partido por los intendentes. En otros distritos más pequeños previamente bajo la jurisdicción de corregidores, se nombraron jueces subdelegados, subordinados estos directamente al intendente, en cuyo nombre y bajo cuya aprobación debían actuar. Su función primordial era la recolección del tributo, su transferencia a las cajas reales y la organización y ejecución de revisitas. ${ }^{15}$ Se abolieron, entonces, el cargo de corregidor y, en 1786, los repartimientos de mercancías que tanto malestar social habían generado desde aproximadamente un siglo atrás. La amplia autonomía de los intendentes para nombrar subdelegados de su predilección e incluso su capacidad de cuestionar los resultados de las elecciones de alcaldes ordinarios de indios fueron seriamente cuestionados desde $1784 .^{16}$

${ }^{14}$ Para el ya drásticamente reducido virreinato del Perú, nuevas intendencias se crearon en Tarma, Trujillo, Lima, Cuzco, Huamanga, Huancavelica, Arequipa y Chiloé. Véase el análisis de las reformas de Carlos III, entre otros, en Fisher 1970; Fisher, Kuethe y McFarlane 1990; y Andrien 2009: 6-7, 9.

15 Ordenanza General 1803: 105.

${ }^{16}$ Las tensiones crecientes entre intendentes y virreyes provocaron que el nombramiento de intendentes se pusiera en manos del virrey según la Real Cédula de 29 de enero de 1792. Sin embargo, estas tensiones hicieron que el efecto de la cédula fuese atemperado ofreciéndole al intendente la oportunidad de proponer una terna para la selección de subdelegados por el virrey (Navarro García 1959: 89). Se introdujeron para la misma época otros cambios en la denominación de ciertos funcionarios e instituciones: el protector de naturales aparecerá designado como «agente protector fiscal de naturales»; los procuradores del pueblo, como "procuradores del juzgado del pueblo de Chorrillos»; 
El corregimiento de Lima y los pueblos circunvecinos fueron fusionados en una misma subdelegatura en 1784, y el subdelegado pasó a ejercer la supervisión directa de los pueblos de indios. ${ }^{17}$ Español y nombrado por el intendente, el juez subdelegado tenía completa competencia en los órdenes judicial, administrativo, económico y militar en el ámbito de los pueblos. ${ }^{18}$ Además, era designado por un término de cinco años y residía en el pueblo de indios cabeza de partido. ${ }^{19}$ En 1784, Santiago del Cercado fue erigido como la cabeza del partido que lleva su nombre; a su jurisdicción pertenecían los pueblos de indios del valle de Lima como San Pedro de Chorrillos, Surco, La Magdalena, Ate, Lurín y Pachacamac. Al igual que los corregidores y párrocos antes de las Reales Ordenanzas de Intendencia, los subdelegados debían presidir las elecciones del Cabildo indígena, requisito sin el cual aquellas no tendrían validez. ${ }^{20} \mathrm{Al}$ entrar a controlar los asuntos de justicia en los pueblos de indios, los subdelegados incorporaron en su nueva esfera jurisdiccional los asuntos relacionados con la repartición de tierras en forma de solares, privando o desplazando al Cabildo indígena de esta potestad en que habían permanecido durante las administraciones reales anteriores. ${ }^{21}$

Las ordenanzas de Carlos III a nivel del espacio étnico pusieron un acento especial en el control del manejo de los bienes de comunidad por parte del subdelegado y, al menos en el caso del virreinato del Río de la Plata, formaron Juntas Municipales para el control directo de los

y el cabildo de Chorrillos, como «cabildo constitucional del Pueblo de San Pedro de Chorrillos» (AGN, Lima, Fácticas, CSC, L5, C137, ff. 35, 64).

${ }^{17}$ Fisher 1990: 81. Pablo Patrón de Arnao, el último corregidor nombrado en 1779, en realidad continuó como primer subdelegado en 1784 por orden del visitador Escobedo.

${ }^{18}$ Fisher 1990: 82.

${ }^{19}$ Navarro García 1959: 88-89.

${ }^{20}$ Artículos 10 y 11 de las Reales Ordenanzas de Intendencia (San Martino de Dromi 1999: 48). Es interesante que el énfasis de las Ordenanzas de Intendencia acerca de las cualificaciones de los candidatos para alcaldes ordinarios del cabildo indígena estuviera puesto en su capacidad para hablar castellano y su vocación por la agricultura o la industria.

${ }^{21} \mathrm{Al}$ parecer esta costumbre de repartir tierras en parcelas individuales por parte de las autoridades étnicas del pueblo también se daba al interior de las comunidades indígenas desde tiempos antiguos de manera autónoma (Ramírez 1996: 72). 
bienes propios y arbitrios de los pueblos de españoles y los pueblos de indios por parte de los representantes del rey. ${ }^{22}$ Ahora el excedente de lo rendido por los bienes de comunidad no permanecería en las cajas de comunidad del pueblo sino que debía ser remitido a la tesorería principal de la provincia y sería directamente administrado por el intendente, el tesorero y el contador, cada uno de los cuales poseería copia de la llave de las cajas reales. ${ }^{23}$ Estas disposiciones expresan la intensidad y los medios con que los monarcas borbones aspiraban a controlar localmente no solo política sino económicamente la «República de indios», e integrarla más eficazmente a los objetivos y la consolidación global del imperio.

En las décadas siguientes se hizo evidente que, a pesar de las prohibiciones expresas de las «Reales Ordenanzas de Intendencia», los subdelegados se involucraron en actividades lucrativas ilegales cuestionando seriamente la efectividad de las ordenanzas de Carlos III para la rectificación de la justicia en los Andes. ${ }^{24}$ Además de la carencia de sueldo, hasta 1803, y la baja comisión que sobre los tributos podían percibir los jueces subdelegados, la aspiración de enriquecimiento con sus posiciones indujo a estos funcionarios a formar alianzas con las élites locales de hacendados, estancieros y comerciantes. En este proceso, los bienes de las comunidades, especialmente sus tierras y recursos productivos, fueron objeto de abusos y usurpaciones por hacendados y estancieros que eventualmente encontraron el apropiado espaldarazo legal en la corte del subdelegado. Como se verá, el Cabildo de naturales de Chorrillos constantemente

22 San Martino de Dromi 1999: 52.

${ }^{23}$ Ib.: 36.

${ }^{24}$ En el artículo 9 específicamente, las Reales Ordenanzas de Intendencia prohibían a los subdelegados e intendentes practicar repartos de mercancías a los indios. Sin embargo, las quejas por la imposición ilegal de estos por parte de los subdelegados se incrementaron a partir de 1786, año en que fueron oficialmente abolidos. Su existencia continuó en el siglo XIX, aún más allá de 1803, cuando las Reales Ordenanzas de Intendencia se modificaron para oficializar el pago de salarios a los subdelegados en un vano intento por controlar su nocivo comportamiento (Fisher 1970: 90-99). También se ratificó en esta nueva Ordenanza General de Intendencia que los subdelegados serían jueces de primera instancia y se abrió la posibilidad que estos nombrasen «tenientes españoles sin sueldo alguno en los Pueblos de Indios» (Navarro García 1959: 129-130). 
tuvo que recordarle al subdelegado cuáles eran sus deberes para con el pueblo, aunque muchos de los argumentos planteados al respecto por los ediles indígenas se estrellarían con un muro de silencio y dilación.

La documentación de tierras en el ámbito de los pueblos del valle de Lima permite abordar el cambio sufrido en la propiedad comunal local y muestra cómo la cultura y la retórica legal del Cabildo indígena articularon tales cambios. Los casos seleccionados para explicar este proceso permiten identificar la producción de un discurso legal desde el Cabildo indígena y detectar los desafíos que, desde dentro y fuera de la «República de indios», se antepusieron a la propiedad comunal y al carácter indígena del pueblo al final del período colonial. Los casos condensados en la siguiente sección revelan la recontextualización del discurso toledano por parte del Cabildo para defender las tierras del pueblo y su autonomía como institución de justicia dos siglos después de la administración de Toledo, a la vez que muestran los argumentos y estrategias legales de aquellos residentes indígenas que reclamaron como suyos los solares del pueblo.

\section{SAN PEDRO DE CHORRILLOS: LA DEFENSA LEGAL DEL PUEBLO DE INDIOS}

Es sorprendente lo poco que se sabe de la historia misma de la formación y el crecimiento del pueblo de Chorrillos en el tiempo colonial. ${ }^{25}$ Sin embargo, no es difícil imaginar que su historia estuvo moldeada en parte por su ubicación de cara al océano Pacífico, haciendo de sus habitantes pescadores de profesión. Otros factores que afectaron similarmente a los demás pueblos del valle de Lima incidieron en la formación históricosocial de San Pedro de Chorrillos. Es común a todos ellos, y a Chorrillos en particular, como se demostrará en este artículo, el haber gravitado en torno a la capital virreinal en varios aspectos cruciales. Los asuntos legales de sus Cabildos estaban cercanamente controlados por los alcaldes ordinarios de la ciudad de Lima, el corregidor y la Real Audiencia. La proximidad geográfica facilitaba y atraía grupos de migrantes a Lima y a la costa norte. Los habitantes de Chorrillos participaban de la economía

${ }^{25}$ Informaciones no confirmadas sugieren que el pueblo fue fundado en 1688 como un pueblo de pescadores. 
de mercado que suplía a la ciudad con mano de obra y alimentos; muchos eran pescadores además de pequeños productores agrícolas y pastores, y a menudo producían bajo relaciones de aparcería y arrendamiento. Se puede decir que sus prácticas de tenencia de la tierra incluían regularmente la compra y venta de tierras y el arrendamiento de las mismas a espańoles e indios que usualmente vivían en los pueblos vecinos. En 1788, San Pedro de Chorrillos tenía 44 hectáreas de tierras cuyo excedente financiaba el pago del tributo, 24 hectáreas que los indios habían comprado individualmente y 12 hectáreas donadas a las cofradías por los indios mismos. ${ }^{26}$

A fines del período colonial, el valle de Lima vivía el efecto de una expansión demográfica que en la práctica convirtió a los pueblos de indios casi literalmente en pueblos de españoles (mestizos, mulatos y españoles). ${ }^{27}$ Estos cambios de la composición demográfica pusieron simultáneamente de relieve los límites de la propiedad comunal y el debilitamiento del Cabildo indígena como ente administrador de la justicia de primera instancia con jurisdicción para la adjudicación de tierras del pueblo. La creciente presión por tales tierras dejó a algunos residentes sin un lugar para vivir, situación que se vio agravada por la tendencia de algunos indios a retener individualmente tierras «de repartimiento» o aquellas que eran del común del pueblo y que constituían la reserva territorial para repartir entre los residentes indios que pertenecían a él.

\footnotetext{
${ }^{26}$ Charney 2001: 57.

${ }^{27}$ Datos demográficos precisos para San Pedro de Chorrillos a comienzos del siglo XIX difícilmente se encuentran disponibles. Para otros pueblos importantes del valle de Lima como Santiago del Cercado sabemos que, en el periodo entre 1731 y 1740 , el total de españoles (españoles, criollos, negros y mestizos) comprendía el 50\% de la población total. Aunque tal cifra decreció en las décadas siguientes, para fines del siglo XVIII los españoles ya eran evidentemente la mayoría (Cárdenas Ayaipoma 1985: 80-81). Considerando el indeterminado número de castas que se fueron instalando crecientemente en el pueblo, queda claro que la población indígena declinó sustancialmente. Según Hipólito Unanue, para 1793, la población de indios en la ciudad de Lima apenas representaba el 7,43\% del total (3912), mientras que los espańoles constituían el 32,7\% (17.215) (Unanue 1793). Para los pueblos de Eten, Callanca, Chiclayo, Ferreñafe e Illimo, en la costa norte del Perú y en la segunda mitad del siglo XVIII, la población indígena disminuyó notablemente mientras que la población de mestizos y de otras castas aumentó (Ramírez 1996: 81-82).
} 
Este fue el telón de fondo en la disputa surgida en el pueblo de San Pedro de Chorrillos, entre 1813 y 1821, la cual enfrentó al Cabildo con una mujer india llamada Agustina Laynes, en torno a la posesión de un solar «de repartimiento» en predios del pueblo. ${ }^{28}$ Desde 1813, el Cabildo había recibido peticiones para la asignación de predios para habitar que no pudieron ser otorgadas por la escasez de tierras. ${ }^{29}$ Asistidos por el procurador del Cabildo, sin embargo, algunos solicitantes, entre ellos Cecilio Olaya, indio originario del pueblo, apuntaban a la disponibilidad de un «sitio blanco» en el barrio de "pueblo viejo». Según la petición, tal lugar «siempre se encuentra acéfalo, o para mejor insinuar, despoblado». En la terminología legal castellana, el término «despoblado» no solo significaba la ausencia de uso u ocupación efectiva, sino que también invocaba la necesidad de ser «repoblado». ${ }^{30}$ En este caso individual, repoblar aludía a que alguien debería hacer posesión efectiva del mismo e ingresar como "poblano" o como residente permanente, pasando a formar parte de la comunidad política del reino.

Cecilio alegaba que por cuarenta años el solar había tenido más de seis «amparados» $\mathrm{y}$ "ni siquiera uno solo ha levantado una pared o un corralillo que indique labor en obsequio de lo prevenido como se ha mandado en las Reales Ordenanzas y de acuerdo al Código de Intendencia». Por tanto, Cecilio pidió ser puesto «en posesión» del dicho lote,

\footnotetext{
${ }^{28}$ AGN, Lima, Fácticas, CSC, 5.137, 1813-1821, ff. 1-81v.

${ }^{29}$ La precariedad de tierras disponibles para repartir entre los indios del pueblo también se registra, por ejemplo, en otros pueblos de la costa durante el mismo periodo. En el pueblo de Usquil (Trujillo), el procurador del pueblo pedía en 1798 que se eximiese de censo a las tierras de la comunidad por la escasez de ellas para repartición entre los miembros del pueblo (Archivo Regional de La Libertad [en adelante ARLL], Usquil, Sign. 2375, L 410, septiembre 6, 1798, ff. 1-3).

${ }^{30}$ Véase el significado de «despoblado» en España y América en Herzog 2007: 525-537. De modo más amplio, señala la autora, «despoblado» era entendido en Castilla como tierra ausente de comunidad y carente de auto gobierno; y, lo más importante, implicaba que el espacio «despoblado» y sus habitantes existían fuera del control político de la monarquía. Por tanto, quienes se hallaren en ese estatus deberían ser forzados a «repoblarse» o reducirse en villas y comunidades de «vecinos». En América, «despoblado» incluía el espacio habitado por indios (en cualquier lugar y actividad, percibido como peligroso), en contraste con aquel habitado por españoles o «poblado» (Herzog 2007: 533-534).
} 
lo cual afirmaba merecer legalmente. ${ }^{31}$ El problema se hizo evidente cuando el Cabildo intentó adjudicar el predio que había sido señalado por el solicitante, el cual resultó siendo disputado. Agustina Laynes, quien alegaba tener «quieta e inmemorial posesión» del mismo, respondió al intento de tal adjudicación elevando un recurso directamente ante la corte local del subdelegado. El agente fiscal protector (anterior protector de naturales), a nombre de Agustina, pidió se le protegiese tal derecho y que «no se le inquiete más por parte del Cabildo». ${ }^{32}$

Cecilio y otros solicitantes posteriores, como José María Villavicencio, cuestionaron la posesión de Agustina con sustento en el prolongado despoblamiento en que se había mantenido el predio en cuestión. Hasta allí, la petición de asignación de este solar corría su curso en el Cabildo indígena. Pero cuando Agustina disputa tal presunción, el proceso legal se sale de las manos del Cabildo y entra en la órbita jurisdiccional del subdelegado. Agustina, o su agente fiscal protector, logra una declaración firmada el 11 de julio de 1818 por parte del tesorero del ramo de tributos del partido del Cercado, Juan Joseph de Leuro, quien había levantado un padrón en el pueblo de donde resulta un argumento capital que pondría en cuestión la autoridad del Cabildo para asignar este solar. En el registro número 39 de tal padrón, aparece la asignación de "una anega y media» de tierra del pueblo a Eusebio Rivas y su esposa Agustina Laynes,

para que como legítimos acreedores a su goce por herencia de sus padres pudieran con su producto mantener su familia y distribuirla en sus hijos [...] pues la especial circunstancia de ser originarios de dicho pueblo y sujetos a las demás obligaciones a que están afectos los constituye en acreedores a que no se les inquiete ni perturbe. ${ }^{33}$

${ }^{31}$ AGN, Lima, Fácticas, CSC, 5.137, f. 1r-v.

${ }^{32}$ AGN, Lima, Fácticas, CSC, 5.137, 1818, f. 34r-v. Agustina parece haber firmado por sí misma la petición.

${ }^{33}$ AGN, Lima, Fácticas, CSC, 5.137, f. 49. Eusebio y Agustina recibieron la asignación en la forma de dos predios. Uno de una anega en el pueblo mismo de Chorrillos y otro de media anega en «la quebrada del barranco». No está muy claro aquí cuál de los dos es el reclamado por el cabildo para la repartición. En este caso específico, el padrón levantado intentaba reinstaurar el pago del tributo en cuatro pueblos que habían sufrido por inundaciones. Pero, además, ofrecía la medida de las tierras de los pueblos y la 
Que el agente fiscal protector exhiba un padrón como "prueba de la posesión inmemorial» de Agustina no deja de llamar la atención en tanto estrategia legal para neutralizar la «temeridad e injusticia con que el común se empeña en perseguir a una anciana infeliz». ${ }^{34}$ Pero más interesante resulta que el juez subdelegado no cuestionara tal expediente como instrumento probatorio, dado que el padrón es un registro de los habitantes del pueblo, mas no necesariamente prueba la posesión de un predio.

Pascual Espichán, procurador del Cabildo indígena de Chorrillos en 1813, lideró el debate legal que tuvo lugar ante la corte del subdelegado local. Espichán presentó al Cabildo las solicitudes de solares a nombre de Cecilio y José María Villavicencio. El escribano del Cabildo, Isidro Vilca, puso por escrito las intervenciones orales de Espichán, atestiguando con su firma las actuaciones oficiales del Cabildo. La discusión de este caso creó un foro legal triangulado entre el Cabildo indígena, el protector de naturales y el subdelegado español. Pascual Espichán sostuvo que Agustina poseía una extensión de seiscientas varas cuadradas que mantenía abandonadas en su totalidad. ${ }^{35}$ A este argumento se sumaba el esbozado en nombre del solicitante José María Villavicencio: «esas tierras están abandonadas y en pampa absolutamente». ${ }^{36}$ Espichan avanzó entonces un argumento incisivo, infiriendo que Agustina estaba asumiendo el solar como si fuera de su propiedad individual y recordándole la relación jurídica fundamental que hacía de la suya una "posesión errónea» que perjudicaba el "dominio precario" que de derecho y supuestamente de hecho ya gozaba el pueblo sobre sus tierras. ${ }^{37}$ En otras

repartición de predios entre los originarios de ellos. Lamentablemente, la fecha concreta de la numeración no aparece. En el momento en que se levantó el padrón Eusebio tenía 41 ańos y Agustina, 35.

${ }^{34}$ AGN, Lima, Fácticas, CSC, 5.137, f. 35. La foliación de este expediente es fragmentaria y discontinua.

${ }^{35}$ Las seiscientas varas equivalen aproximadamente a 0,16 hectáreas, más o menos la extensión de una anega y media (fanegada y media).

${ }^{36}$ AGN, Lima, Fácticas, CSC, 5.137, ff. 38, 48.

${ }^{37}$ Según el procurador del cabildo, y en contradicción con lo declarado más arriba por Leuro, Agustina había presentado cierta documentación, ausente en el expediente, indicando que el predio lo obtuvo "en buena memoria de un indio" que a su muerte 
palabras, le recordó que las tierras del pueblo eran «de repartimiento»y no podían ser apropiadas individualmente. Según el procurador Pascual Espichán,

no teniendo en ellas los indios más dominio que el precario, no pueden disponer de ellas como propias por corresponderle a SM el dominio directo. $Y$ en cualquier dejación [...] es incontrovertible que corresponden al soberano el que por efecto de su grata beneficencia a los indios ha prevenido en las leyes y ordenanzas del reyno. Es por eso que he manifestado que dichas tierras se le den en reparto a los indios que mas las necesiten para que formen ranchos, vivan en reducción y se haga más extendible el pueblo. ${ }^{38}$

Durante este largo pleito el Cabildo insistió en la necesidad de otorgar las tierras del pueblo a los indios para que residieran allí. Es un argumento de raigambre toledana racionalizador del programa general de reducciones, claramente expresado en las Ordenanzas del virrey en 1569-1581 y también enraizado en las políticas de repoblamiento en España en el siglo XVIII. Toledo urgió a los indios a «reducirse» en los nuevos pueblos que se fundaren y para ello ordenó que se les asignasen solares donde pudieran habitar y cultivar para su manutención. El propósito colonizador era poner a los indios dispersos bajo el control político, económico y religioso más directo de España en los Andes. Al argumentar que la repartición de tierras era "para que formen ranchos, vivan en reducción y se haga más extendible el pueblo», el procurador del Cabildo indígena aludía también a las preocupaciones renovadas de los Borbones del siglo XVIII sobre la necesidad de repoblar los pueblos «despoblados». ${ }^{39}$ En la petición elevada a nombre de Villavicencio en 1817, Espichán le recuerda al subdelegado que

le encargó pagar misas por su alma con el producto del predio. Espichán no escatima la oportunidad para acusar a Agustina de no haber cumplido con tan sagrado deber ya que las tierras continuaban abandonadas.

38 AGN, Lima, Fácticas, CSC, 5.137, f. 35r-v.

${ }^{39}$ Herzog 2007: 511-522, 528, 536-537. Según la autora, las «repoblaciones» habían empezado a discutirse en Espańa desde la Edad Media y, desde entonces hasta la segunda mitad del siglo XVIII, trataron de implementarse con variados resultados. En América, desde el siglo XVI, tales «repoblaciones» fueron dirigidas a congregar principalmente a espańoles, pero también a mestizos y mulatos que se hallaren en "despoblados» y peligrosamente fuera del control del Estado colonial. Se dieron una serie de leyes con diverso 
su jurisdicción se halla reencargada por las leyes para que vigile y cuide a esta gente miserable aunque tan privilegiada. Las leyes de este reyno son muy claras a este respecto pues se circunscriben a prevenir [que] corregidores y subdelegados hagan los repartimientos de tierras conforme a la necesidad del indio. Con que asi lo encargan a la tenor de nuestras leyes municipales, asi por ellas como por hallarme con hijos sin tener donde habitar [...]. Por tanto pido a VS se sirva librar mandamiento de posesión del terreno que los alcaldes juzguen más conveniente. ${ }^{40}$

Cabría preguntarse por qué se invocaba el argumento reductor más de dos siglos después, en un momento en que los pueblos mostraban precisamente sobrepoblamiento. Tal clamor expresa la precaria representación de la población indígena en la estructura demográfica del pueblo a fines del período colonial, si pensamos que la tendencia demográfica es similar a la experimentada en El Cercado por los mismos años. Los representantes del concejo de gobierno de Chorrillos frecuentemente aludían a la escasez de tierras del común para repartir, lo cual motivó una campaña legal que por décadas lideraron los cabildos étnicos del valle de Lima por la recuperación del carácter fundamentalmente indígena de los pueblos. Visto así, los argumentos toledanos del momento inicial de las reducciones potencialmente cobraron vigencia como expediente argumentativo legal en circunstancias posteriores en que tanto las tierras como la población india de los pueblos claramente disminuían.

Aunque el Cabildo instó al subdelegado de diversos modos a que removiese inmediatamente a Agustina Laynes de la posesión por abandono, el proceso se dilató por tres años más sin mayor novedad. En 1821, asistimos a un Cabildo indígena exasperado por la inhabilidad del subdelegado para responder a las peticiones de mandamiento de amparo provenientes de nuevos residentes para usufructuar el solar que retenía Agustina, aparentemente sin ejercer su uso o usufructo. No hay en la documentación prueba ni señal de esfuerzo alguno por parte de Agustina

efecto en lugares como Puebla (1531), Santo Domingo (1538), Zaruma (Audiencia de Quito, 1593) y Chile (1703, 1712, 1716, 1730, 1740), además de Nueva Granada, Venezuela, Guatemala y Río de la Plata en distintos momentos del siglo XVIII. ${ }^{40}$ AGN, Lima, Fácticas, CSC, 5.137, f. 36. El énfasis es mío. 
para demostrar el uso efectivo del predio. Por tanto, el Cabildo reclama su inspección y reversión inmediata por abandono. Los argumentos legales del nuevo procurador del Cabildo, Pedro Cabañas, presentan descarnadamente el problema de tierras que atraviesa el pueblo, a través del ejemplo del solar que Agustina se rehúsa a devolver:

Debemos suponer que este gran terreno ha estado acéfalo y abandonado muchos ańos; [...] debemos suponer que estas tierras se repartieron a la antecesora de Laynes cuando era muy corto el número de pobladores de este pueblo. Hoy el número se ha aumentado y a V.S. le consta el estado de abandono en que está dicha tierra, que dio lugar a la providencia de 4 de Junio de $1818 .{ }^{41}$

Para persuadir aún más al subdelegado de la urgencia de reasignar las tierras en poder de Agustina, o quizás para ejercer más presión sobre él, el Cabildo aplicó una encuesta entre los pobladores indios de San Pedro de Chorrillos y encontró que un total de 46 «ciudadanos» con hijos carecían de vivienda en el pueblo. ${ }^{42}$ Ya en los años cercanos a la independencia del Perú, los indios del pueblo de Chorrillos aparecen identificados como ciudadanos y, en lo que sigue, el discurso letrado más sofisticado de Pedro Cabañas, común en la esfera legal del siglo XVIII tardío y el siglo XIX, tomó cuerpo como argumento legal. El procurador del pueblo pidió que las tierras «amparadas» a favor de Agustina se destinaran para repartimiento, expresando esta vez su preocupación por la salud pública del pueblo ya que el confinamiento empezaba a ser notorio por la falta de espacio y la consiguiente propagación de «enfermedades contagiosas», no sin reclamar al juez su deber de contribuir al poblamiento del pueblo con residentes indios. ${ }^{43} \mathrm{El}$ procurador apeló así al propósito borbón de la época relacionado con la necesidad de ocupar efectivamente el territorio de manera civilizada y en el fomento de las

${ }^{41}$ AGN, Lima, Fácticas, CSC, 5.137, f. 49r-v. La providencia no está en el expediente, pero no es difícil imaginar que le fue requerido a Laynes demostrar el uso que daba al predio. Al parecer su respuesta elocuente y sin palabras fue tender una cerca alrededor del mismo señalando su sentido de propiedad individual del predio.

${ }^{42}$ AGN, Lima, Fácticas, CSC, 5.137, f. 78r-v.

${ }^{43}$ Ib.: f. $79 \mathrm{v}$. 
labores agrícolas, para la consolidación del orden político español en los espacios étnicos tradicionalmente asumidos como territorio fuera de control.

Pedro Cabañas presentó escuetamente tres argumentos que intentan sacudir la larga indiferencia del juez subdelegado. Primero, que las tierras del pueblo no eran propiedad privada: «Las prenotadas tierras como todas las que se hallan en la jurisdicción de los pueblos son de repartimiento y ningún indio ha adquirido propiedad por la asignación». ${ }^{44}$ Segundo, que ni Agustina ni sus antecesores hicieron composición de tierras alguna con el rey ni tenían título alguno al respecto. Y si lo tuvieren, sería procedente reembolsarle lo pagado por tal composición para que así la tierra quedara disponible para su repartimiento entre aquellos indios del pueblo que la necesitaren. Tercero, y muy revelador,

que la india Laynes por ser mujer y por tanto exenta de servicio no debe gozar reparto y mucho menos cuando disfruta sitio importante en el pueblo hasta el extremo de haber vendido dos por no necesitarlos. Así está que la prueba real de no necesitarlos la susodicha ha sido el haber mantenido ese terreno abandonado sin cultivarlo hasta ahora en que, temerosa que se le prive su goce, lo ha cercado. ${ }^{45}$

El discurso legal de la exclusión de Angelina de la posesión por ser mujer hace evidente el estatus de género implícito en la ley, la interpretación de lo que significaba ser miembro de la comunidad del pueblo y la decisión acerca de quiénes entonces podían gozar plenamente de los beneficios que tal membrecía acarreaba. El derecho al otorgamiento de un solar en usufructo temporal era la expresión del carácter comunal de la propiedad de las tierras del pueblo de indios. Pero este derecho también acarreaba obligaciones para los beneficiarios, particularmente la de prestar servicios de trabajo en las labores de mantenimiento del pueblo como las obras públicas, la limpieza de los canales de riego y el servicio civil en el Cabildo. En la interpretación de Cabañas, Agustina, por ser mujer, estaba exenta de prestar servicios, lo que automáticamente la

44 Ib.: f. 80 .

$45 \mathrm{Ib}$. 
excluía de recibir asignaciones de tierras y ejercer su posesión y usufructo a nombre propio. Lo que Cabañas no admitía, sin embargo, era que ella había sucedido por derecho propio en la posesión a la muerte de sus padres y de su marido, a cuyo nombre estaba al parecer el mandamiento de amparo original.

Por otra parte, cabría pensar que la ley ofrecería a la mujer alguna suerte de compensación, ya que los maridos, hijos o padres solo podrían cumplir con sus obligaciones comunitarias con el pueblo si sus esposas, madres o hermanas proveían a su vez el trabajo requerido para la manutención de aquellos durante sus jornadas de prestación de servicios al pueblo, por no mencionar el mismo tipo de trabajo entregado por ellas regularmente durante el año. Tampoco parece el procurador del Cabildo de Chorrillos admitir que la ley misma otorgaba a las mujeres la sucesión en la posesión a la muerte de su padre o marido poseedor. ${ }^{46}$ Es importante anotar que en el contexto del servicio personal, «el sexo débil ocurre a la labor de chacras y fuera de ella al zurcido y tejido de medias calcetas de lana y algodón». ${ }^{47}$

Las razones de Espichán y Cabańas fueron insuficientes y el juez subdelegado finalmente expidió un mandamiento de amparo a favor de

${ }^{46}$ Antecedentes de tales beneficios otorgados a mujeres en virtud de esta ley hay muchos en los registros documentales coloniales. En 1594, por ejemplo, en el pleito que enfrentaba a Cathalina Patta con Joan Chayca y otro indio por diez topos de tierras llamadas Totorapampa y Rumichaca en Huamanga, el juez comisiona al póstumamente famoso don Felipe Guaman Poma de Ayala, «lengua», para conducir la «vista de ojos» o inspección de vacancia y linderos y ofrecer su veredicto. Según el escribano Joan López, «viendo averiguado la verdad de a quién legítimamente pertenecían estas tierras», Guaman Poma «halló y conoció ser dichas tierras de la dicha Cathalina Patta en possessión antigua y heredadas de su padre y que ninguna otra persona ni indio era dueño de ellas». Básicamente compartía el argumento del protector de naturales, Esteban Vega, quien aseguraba que las tierras «pues son suyas de posesión antigua quieta y pacíficamente y anssi». El juez confirma el amparo de posesión a Cathalina y se le emite título o amparo, advirtiendo que «nadie ni el cacique puede intentar apartarla de su possession porque es antigua y quieta. Y que estas tierras no las puede vender sin una orden especial del gobierno» (Pereyra Chávez 1997). En el caso que nos concierne en este ensayo, la condición de mujer fue estratégicamente presentada por el agente protector, en nombre de Angelina Laynes, asimilándola a la condición de «miserable»: Angelina no debía ser inquietada por ser «vieja, pobre y viuda y tiene cinco hijos» (AGN, Lima, Fácticas, CSC, 5.137, f. 35). ${ }^{47}$ Zabala 1978-1980, III: 95. 
Agustina Laynes, sin objetar el argumento del abandono de su predio a pesar que la ley toledana prescribía las asignaciones de solares con el propósito exclusivo de propiciar su uso por el beneficiario para su habitación y efectiva posesión. Llegados a este punto, debemos preguntarnos por qué el Cabildo mantuvo en alto su batalla legal por tantos años, a pesar de la inefectividad del juez. En primer lugar, el Cabildo consistentemente presionó al subdelegado para que autorizase la asignación de estos solares ya que eran cruciales para preservar la condición de San Pedro de Chorrillos como pueblo de indios en medio del embate migratorio de españoles, mestizos y mulatos en el siglo XVIII. En segundo lugar, independientemente del resultado del pleito, el que Agustina siguiese «amparada» representaba una clara amenaza para la reproducción social y étnica del pueblo ya que, como ella, otros retendrían tierras comunales en manos privadas, sustrayéndolas en la práctica del fondo de tierras comunales disponible para sostener un número mayor de residentes indios.

Por último, la defensa del derecho de posesión y usufructo de las tierras del pueblo era para el Cabildo la defensa de sí mismo como ente autónomo en el manejo social y de justicia del pueblo. La reticencia de Agustina a entregar el predio al Cabildo, hizo que las decisiones de repartición de solares se salieran aún más de su control y quedaran en manos del juez subdelegado, sin recurso de apelación una vez que el mandamiento de amparo había sido emitido. Esto también acrecentaba la ansiedad del Cabildo por la sobrevivencia del pueblo como espacio étnico y por su propio desplazamiento como entidad autónoma de gobierno indígena ante el creciente control político local ejercido por el subdelegado, como producto de las reformas borbónicas de 1777 y las Ordenanza de Intendencia en 1784.

\section{EXPERIENCIAS REITERADAS}

No fue esta la primera vez que San Pedro de Chorrillos enfrentaba el asedio de la propiedad privada individual y el desafío a su existencia como pueblo de indios o espacio étnico. Solo como un ejemplo, analicemos el pleito iniciado en marzo de 1800 en que el Cabildo indígena de Chorrillos, y el procurador Isidro Vilca en su nombre, se engarzaron en 
una batalla legal por la defensa de ciertas tierras del pueblo en que los indios llevaban a cabo una edificación. El pleito surgió cuando doña Micaela Villegas respondió visiblemente, asumiendo como suyos tales predios, e iniciando allí su propia construcción. ${ }^{48} \mathrm{El}$ Cabildo pidió entonces al juez subdelegado el derecho a ser oído en la defensa de las tierras y poder así oponerse a la construcción que Villegas había iniciado. El juez subdelegado hizo caso omiso y, en cambio, remitió al Cabildo una providencia de amparo emitida por la Audiencia a favor de Micaela Villegas. Adicionalmente, el juez conminó a Vilca y al pueblo a que «no embaracen mis partes la fábrica que se intentaba edificar». ${ }^{49}$ Vilca protestó arguyendo que se había ignorado la jurisdicción del Cabildo en la determinación de si Micaela Villegas cualificaba o no para la posesión y la obtención de un amparo; según Vilca, "el Cabildo no ha sido oído». ${ }^{50}$

El problema que atravesaba el pueblo de Chorrillos hasta 1800 queda expresado en el punto central del procurador del pueblo: «estas tierras son de repartimiento de indios». Además, añadió que Villegas no había presentado el "título legítimo de dominio» por medio del cual obtuvo el predio directamente del rey por medio de una "composición de tierra». ${ }^{51}$ Debido a que, al menos en la teoría legal castellana, las tierras del común eran del dominio real, para tener licencia de venderlas se requería dispensación del rey "componiéndolas», es decir pagando a este el derecho de composición de tierras.

Conociendo al parecer a la letra el estatus legal de las tierras del común, el procurador indígena Isidro Vilca puso de presente al juez esta situación, quizás conocedor de que Micaela no había pagado compo-

${ }^{48}$ Dadas la cronología y la localización, la Micaela Villegas en cuestión podría ser la famosa "Perricholi», en su edad madura, quien escandalizara a la sociedad limeña en la segunda mitad del siglo XVIII por su romance con el virrey Manual de Amat y Juniet. De carácter decidido y emprendedor, Micaela debió tejer una red social de influencia entre algunos miembros de la élite que debieron serle útiles para que la Audiencia le extendiera una providencia de amparo sobre tierras que al parecer correspondían al pueblo de Chorrillos.

${ }^{49}$ AGN, Lima. Fácticas, CSC, L2, C42, 47r-v.

${ }^{50}$ AGN, Lima, L1, C645, marzo 27, 1800, f. 17.

${ }^{51}$ Ib.: f. $17 \mathrm{v}$. 
sición. En cualquier caso, Vilca replicó de antemano que de lograr la composición el debido procedimiento de venta habría sido a través de subasta pública, en cuyo caso el protector de naturales debió publicar la apertura del proceso de venta de la tierra dando prioridad a las "posturas» del Cabildo a nombre del pueblo antes que a los compradores españoles. Pero si Micaela lo compró o lo obtuvo de un individuo que "carecía de facultad para ello», continúa Vilca, entonces su dominio sobre el predio no era válido. ${ }^{52}$ De este modo, el Cabildo de Chorrillos aspiraba a retener la propiedad comunal de las tierras de repartimiento y asignarlas en usufructo a nuevos miembros de la comunidad del pueblo. Entendiendo, como se verá, que tal acción de Villegas era de hecho un ejercicio de propiedad (dominio) sobre tierras del pueblo, el Cabildo demanda de nuevo que se le requiera a Villegas «la edicción de los títulos», es decir que exhibiera los títulos que la acreditaban como propietaria para ser inspeccionados y así substanciar su derecho. ${ }^{53}$ No hay señal en el expediente que el juez ordenó pedirle a Villegas sus títulos.

La compleja defensa que, a nombre del pueblo, Isidro Vilca elevó entonces a la Audiencia de Lima muestra su excepcional familiaridad con un idioma legal altamente especializado, quizás prefigurando el más propio estilo técnico-procesal del siglo XX. El letrado indígena desafía directamente el conocimiento legal del juez subdelegado desplegando su capacidad de interpretación de la ley frente a la Audiencia misma para afirmar su caso. Primeramente, aclara que la providencia del Superior Gobierno «restringía el proveído solo al amparo y en ningún modo se ampliaba acerca de la fábrica». ${ }^{54}$ En otras palabras, explica que el subdelegado no entendió el límite de un mandamiento de amparo con respecto a un título de propiedad, enfatizando que el amparo no le da

\footnotetext{
52 Ib.: f. 18.

53 "A pesar de habérsele requerido, Micaela Villegas no ha demostrado tal título». Y si lo tuviera, Vilca prosigue, el cabildo habría incluso negociado con ella para reembolsarle su dinero, incluyendo las mejoras, y poder recuperar así las tierras del pueblo para su repartimiento. Ib.: f. 18 .

${ }^{54}$ Ib.: f. $47 \mathrm{v}$.
} 
a su beneficiario el dominio sobre la tierra como para llevar a cabo una construcción; es decir, no la hace propietaria del terreno.

En tales circunstancias, Isidro Vilca sostiene que sin tener el Cabildo acceso a los títulos que Villegas debería exhibir, y sin tampoco haberse escuchado hasta ese momento al protector de naturales de la Audiencia, continuar con la obra de Villegas sería «ejercitar un acto de dominio que dice contradicción con la naturaleza del juicio posesorio» en cuestión. Por tanto, Vilca pide al Superior Gobierno que se suspenda la obra de Villegas porque «el procedimiento del subdelegado es incombinable con la providencia de Su Excelencia». Según el procurador de indios, hay claramente un error de procedimiento, por lo que pide que «se progrese por sus debidos trámites, y que el posesorio no se confunda con el petitorio». Además, aclara la diferencia que habría entre ser protegido con un amparo y pedir autorización para una construcción, lo cual se traduciría en un acto de propiedad. ${ }^{55}$

Vilca culminó su discurso aseverando que, en el trasfondo de este pleito, se estaba infringiendo un derecho más fundamental en contra de los indios. Dada la falta de los títulos de Villegas y la imposibilidad de inspeccionarlos, «alterar la sustanciación es convertir la protección que debe emplearse para con los indios en un perjuicio irresarcible si dicha fábrica no se suspende». En otras palabras, al amparo emitido por la Audiencia a favor de Villegas, el procurador le opuso el derecho de los indios a la protección (otra forma de amparo) que la Audiencia estaría en peligro de transgredir de no impedir la edificación de Micaela Villegas.

La historia de la posesión y propiedad del terreno en cuestión que dońa Micaela intentó demostrar exhibiendo el amparo obtenido de la Audiencia, aunque no el título mismo de la propiedad, ejemplifica la incursión de personas no indígenas en las tierras comunales de los pueblos de indios también a comienzos del siglo XIX. Los mecanismos utilizados por Micaela para lograr este amparo sin ser india originaria del pueblo no son claros en el expediente, como no son del todo claros tampoco los mecanismos de adquisición de tierras del pueblo en el primer caso anali- 
zado. Lo cierto es que siempre hubo cierta opacidad en los procesos legales mediante los cuales españoles, criollos, mestizos y algunos indos ricos terminaron aposentándose y reclamando derechos de propiedad sobre terrenos que el Cabildo indígena reclamaba como propiedad del común.

En el presente caso, al parecer, dońa Micaela había recibido el predio por donación de Antonio Barba de Cabrera, español y Caballero de la Orden de Santiago, quien a su vez los había 'comprado' de doña Juana María de los Santos, al parecer india de una de las élites étnicas residentes en el pueblo. Ella alegaba tener títulos de «dominio y propiedad» supuestamente verificados por el agente fiscal protector de naturales, y pidió licencia al juez subdelegado del partido del Cercado para vender la tierra. Pero no lo hizo en subasta pública, como se suponía entonces que debía hacerse por ser venta de bienes raíces del pueblo de indios, donde ellos tendrían prelación para hacer "posturas", sino que vendió directamente a Don Antonio Barba, quien luego donó la tierra a dońa Micaela Villegas. No queda muy clara en el documento la relación de propiedad de Juana María con respecto a la tierra en cuestión. ${ }^{56}$

Cada vez que pudieron, los cabildos lucharon de diversos modos por retener la propiedad sobre sus tierras, incluso apelando a la compra de ellas, particularmente cuando se llevaban a remate por considerarse tierras «sobrantes». ${ }^{77}$ En síntesis, Vilca concluye que el juez subdelegado que

${ }^{56}$ Así como los caciques en sus ayllus o comunidades, las autoridades indígenas no cacicales de los pueblos arrendaban tierras de comunidad a españoles y otros sujetos externos al pueblo para solventar deudas de tributos u otros gastos y obligaciones del común. Muchas tierras de comunidad habían sido aparentemente forzadas a censo a partir de la creación de la Caja General de Censos por Toledo en la década de 1570. Por diversas razones, las tierras del común entraban en operaciones de venta que generaban o no títulos de propiedad, oportunidades que eran aprovechadas inclusive por miembros afluentes de las mismas élites indígenas para hacerse propietarios. El caso en cuestión pareciera tener vagamente este perfil. En otros casos, el cabildo indígena mismo actuó como agente arrendador o vendedor de tierras que eran «de repartimiento» del pueblo. Entre los muchos ejemplos de esta práctica en el Cercado, véase AGN, Protocolo Notarial, No. 187, 1790-1808, ff. 141v-142; 142v-143v; 324; 239-239; 324; 364.

${ }^{57}$ Ramírez sostiene que, en el norte del Perú, las tierras así denominadas eran en realidad tierras que el pueblo no usaba, no porque sobraran sino porque no tenían acceso a la necesaria irrigación para ser puestas en producción (Ramírez 1996: 79). Con la 
confirmó el amparo a Villegas, al ignorar la jurisdicción del Cabildo en la determinación de quién cualificaba para un amparo de posesión, al no entender la diferencia entre amparo de posesión y derecho de dominio o propiedad y, finalmente, al no requerirle a Villegas la presentación de los títulos que probarían su derecho de propiedad, cometió errores de procedimiento. Así, demanda esencialmente la suspensión de la edificación de Villegas que es de hecho un desafío a la propiedad comunal de Chorrillos y defiende su demanda en la necesidad imperiosa de tierras para distribuir entre los miembros de la comunidad del pueblo. El pleito parece quedar en este punto, sin que aparezca en el expediente una anulación del amparo dado a Micaela Villegas o nuevas acciones procesales que reversaran la situación que originó el pleito. ${ }^{58}$

\section{REFLEXIONES FINALES}

Ante el avance sostenido de las relaciones coloniales fundamentadas en la propiedad privada individual, el Cabildo indígena de San Pedro de Chorrillos, entre varios otros del valle de Lima, desplegó su arsenal legal e institucional para defender el carácter indígena del pueblo partiendo de su principio cohesionador primordial, la propiedad comunal de sus tierras y el derecho a su usufructo por parte de los indios originarios que acudiesen al uso efectivo de ellas y a la contraprestación de servicios al común del pueblo.

Uno tras otro, los procuradores indígenas del común activaron el dispositivo discursivo y la acción legal en la corte del subdelegado y ante la Real Audiencia de Lima, ocasionalmente situados en la orilla opuesta al protector de naturales. De esta manera, en un esfuerzo por detener

intención de repartirlas a los miembros de la comunidad, algunos kurakas intentaron también «re-comprar» tierras comunales que habían perdido tal carácter al ser vendidas a españoles o criollos. El término tierras «sobrantes» o "vacas» también se usó en el siglo XVI y XVII para hablar de las tierras que quedaron 'disponibles' luego de la catástrofe demográfica indígena que acompańó y siguió a la invasión española.

${ }^{58}$ Casos de esta naturaleza son recurrentes en el archivo. Véase, entre otros casos similares para el valle de Lima, los siguientes: AGN, Lima, CSC, 5.137, 1804, ff. 318v-382v; 1.34, 1786, f. 7; 2.69, 1803, ff. 45-49v; 4.89, f. 181; 4.92, 1814. 
la pérdida de poder decisorio del Cabildo indígena en la definición de las políticas de distribución y el uso del espacio residencial y productivo en el pueblo, defendieron las «tierras de repartimiento». Las decisiones del juez subdelegado, y al parecer también de la Audiencia, tendieron a favorecer el uso del espacio agrícola y residencial del pueblo como una propiedad personal lesionando el elemento cohesionador del "común».

Las reformas borbónicas de 1777, las Ordenanzas de Intendencia de 1784 y su modificación en 1803, en particular, desplazaron más certeramente el poder jurisdiccional del Cabildo indígena en materia de tierras del común hacia el juez subdelegado (antiguo corregidor), quedando el Cabildo relegado al mero ofrecimiento de la información requerida por el juez. Quizás tales actuaciones no sorprendieron a muchos en el pueblo ya que el subdelegado, español o criollo, se constituyó en uno de los más deletéreos elementos en la continuación de las prácticas ya ilegales de repartos que paradójicamente las reformas borbónicas pretendieron, sin éxito, aniquilar. ${ }^{59}$

En su afán de reafirmar el control político a todo nivel, las Ordenanzas de Intendencia hicieron imposible al Cabildo indígena la continuación de su jurisdicción local en materia de asignación de solares para usufructo familiar. A través de "mandamientos de amparo», muchas veces de oscura procedencia, el juez subdelegado y la Audiencia favorecieron a espańoles e indios acomodados, con la transferencia de propiedad lo cual distorsionó el propósito colectivo de las tierras del común. Estos usurpadores de la propiedad comunal en la práctica dispusieron de ellas a discreción como propiedad personal y, al retenerlas en ese estatus, contribuyeron a drenar el fondo de tierras comunales disponibles para la reproducción del grupo de residentes indígenas del pueblo. Este comportamiento amenazaba por siempre su sobrevivencia como espacio étnico y la jurisdicción del Cabildo indígena en la distribución de la justicia local en materia de tierras, base de la existencia misma del pueblo y su Cabildo. La disolución de este rezago de colectividad se precipitaba con mayor rapidez si se entiende que la usurpación de tierras traía frecuentemente

${ }^{59}$ Fisher 1970. 
aparejada la usurpación de aguas, pastos y otros recursos del común por parte de españoles y criollos. ${ }^{60}$

Enmarañados en juegos de alianzas políticas y económicas locales, el juez subdelegado y los jueces de la Audiencia ejercieron su poder judicial en los conflictos por la posesión de las tierras del pueblo con un criterio privatizador que ya prefiguraba el fin del largo proceso de disolución legal de la propiedad corporativa municipal y la desintegración final de las tierras de comunidad como base material y simbólica de la comunidad del pueblo de indios. El proceso de privatización de tierras comunales continuó expandiéndose en Chorrillos y en la mayor parte del Perú después de la Independencia (1825) y constituiría una de las piedras angulares de las reformas liberales del siglo XIX en los países andinos, escena apenas ideal para la entrada triunfal de la agricultura comercial del capital y sus congruentes políticas de tierras del período subsecuente. ${ }^{61}$

Vistos estos desafíos legales a la propiedad comunal en su conjunto, se hace evidente que la esfera del Cabildo y la corte del subdelegado se convirtieron en verdaderas plataformas de argumentación legal indígena sobre el sentido de la posesión y el derecho al usufructo en un momento histórico de maduración y declinar del modelo antiguo de reducción. Doscientos años más tarde, las contradicciones del colonialismo y sus principios legales hegemónicos hicieron inevitable la colisión del

${ }^{60}$ Casos de usurpación de aguas aparecen con frecuencia en distintas regiones. Ejemplos para la costa norte se encuentran en: ARLL, Trujillo, Sign. 2829, mayo 2, 1816 (Guanchaco); Sign. 2831, septiembre 2, 1816; Sign. 2834, octubre 25, 1817 (San Juan Bautista de Simbal); Sign. 2832, marzo 8, 1817 (Parroquia de San Sebastián); Sign. 2835, diciembre 4, 1817 (Guaman); Sign. 2833, marzo 12, 1817 (Lima); Sign. 2836, julio, 1818 (Mansiche, San Esteban, Guanchaco y Moche); Sign. 2837, julio 7, 1820 (Chocope Trujillo). Véanse ejemplos adicionales de tales transgresiones a la propiedad comunal en la misma región en Ramírez 1996: 74, 84 y 85.

${ }^{61}$ Gade y Escobar muestran el arco histórico de tal transformación para algunos pueblos del suroccidente de Cuzco. Para el pueblo de San Andrés de Chamaca, por ejemplo, los autores señalan que mientras en el siglo XVI el pueblo tenía 69.000 hectáreas de tierras comunales, para 1980, tales tierras solo comprendían 30.000 hectáreas, y el resto se transformó en haciendas de ganado de propiedad privada individual y tierras de pastoreo de ovejas y llamas; por su parte, el distrito vecino de Livitaca experimentó una pérdida de 20.000 hectáreas en doscientos años (Gade y Escobar 1982: 442). 
concepto castellano de comunidad, fundamentado en la propiedad comunal aparejada al derecho de usufructo, con el derecho más prevalente de propiedad individual, sustento de las relaciones de mercado y expansión imperial en los albores del capitalismo, que hacían menos prioritaria ya la integración de los indios al proyecto político imperial.

En todo este proceso sobresale el rol del procurador del Cabildo como exponente de la sofisticada cultura letrada de las autoridades indígenas del pueblo en las postrimerías del colonialismo español. Su conocimiento y uso estratégico de los instrumentos notariales tales como la creación de padrones para sustentar la carencia de tierras de repartimiento, el uso y acopio documental del archivo del Cabildo y la Caja General de Censos para investigar la historia de los amparos y títulos de tierra pertinentes a los pleitos en cuestión, el uso del poder de convocatoria del Cabildo a la comunidad para comunicar su necesidad de tierras, y la confección del discurso legal de las reducciones y el repoblamiento ya entrado el siglo XIX expresan la capacidad política de estos actores indígenas del mundo colonial que agonizaba. Ellos desplegaron tales instrumentos y estrategias en la defensa de un nuevo sentido de comunidad y autonomía étnicas que, con los años, en el valle de Lima, se había ya desplazado francamente del cacicazgo al pueblo de indios de manufactura colonial. Así, el acumen intelectual de estos actores legales de la «República de indios», en la alborada del siglo XIX, sugería una respuesta tácita al proyecto borbón en su expresión local de control político, revelando con su inmersión creativa en el ámbito letrado de la argumentación legal un liderazgo político que intentaba rescatar los últimos vestigios de comunidad que permanecían aún en los pueblos del valle de Lima al final de la experiencia colonial.

Desde la perspectiva historiográfica, al analizar con detenimiento las actuaciones legales de los representantes indígenas de la «República de indios» que se generaban desde los cabildos de naturales, se obtiene una percepción más fina del significado de comunidad indígena en contextos urbanos y de los cambios en el concepto de autoridad indígena en las postrimerías del colonialismo espańol. Si bien la documentación parece registrar la desintegración de la propiedad comunal, lo que contraería aún más la presencia india en el propio pueblo de indios, también ella 
permite sugerir un sistemático esfuerzo de empoderamiento político con raigambre legal por parte de las autoridades del Cabildo. Muy importante para la etnohistoria, finalmente, es detectar el recurso político-legal por parte de la autoridad indígena a la institucionalidad del Cabildo mismo como plataforma discursiva y de diálogo, no siempre recíproco, con el Estado colonial. Este recurso revela la profunda conciencia legal indígena y su intencionalidad política. Expresada en el florecimiento de una cultura legal refinada, esta conciencia alude al poder de moldear el uso e interpretación de la ley desde dentro de la célula más básica del Estado colonial (los cabildos de naturales) y desde allí disputar el intento borbónico de subordinar la autonomía del pueblo de indios, en momentos en que las comunidades rurales enfrentaban el impulso abolicionista de los cacicazgos. La dimensión política en el discurso legal de los procuradores de Cabildo indígenas, en últimas, quedaba expuesta al articular la idea más global de la imposibilidad de la justicia colonial para mantener en pie aún las más precarias formas de comunidad étnica por ella misma creadas.

\section{BIBLIOGRAFÍA}

Andrien, Kenneth J. 2009. «The Coming of Enlightened Reform in Bourbon Peru: Secularization of the 'Doctrinas de Indios', 1746-1773». En Paquette, Gabriel B. (ed.). Enlightened Reform in Southern Europe and its Atlantic Colonies, $c$. 1750-1830. Farnham: Ashgate, 183-202.

Ballesteros, Tomás de. 1752. Tomo primero de las ordenanzas del Perú. Lima: Imprenta de Francisco Sobrino y Bados.

Cárdenas Ayaipoma, Mario. 1985. «Demografía del Pueblo de Santiago del Cercado". Revista del Archivo de la Nación. Núm. 8: 79-110.

Charney, Paul. 2001. Indian Society in the valley of Lima, Peru, 1532-1824. Lanham, Nueva York y Oxford: University Press of America.

Dueñas, Alcira. 2010. Indians and Mestizos in the Lettered City: Reshaping Justice, Social Hierarchy and Political Culture in Colonial Peru. Boulder: University Press of Colorado.

Fisher, John R. 1970. Government and Society in Colonial Peru. The Intendant System 1784-1814. London: University of London y The Athole Press.

Fisher, John R., Allan J. Kuethe y Anthony McFarlane (eds.). 1990. Reform and insurrection in Bourbon New Granada and Peru. Baton Rouge: Louisiana State University Press. 
Gade, Daniel W. y Manuel Escobar. 1982. «Village Settlement and the Colonial Legacy in Southern Peru». Geographical Review. Vol. 74, núm. 4 : 430-449.

Herzog, Tamar. 2007. «Terres Et Déserts, Société Et Sauvagerie: De La Communauté En Amérique Et En Castille À L'époque Moderne». Annales. Histoire, Sciences Sociales. Vol. 62, núm. 3 : 507-538. https://doi.org/10.1017/ s0003161500002303

Herzog, Tamar. 2013. "Colonial Law and 'Native Customs'. Indigenous Land Rights in Colonial Spanish America». The Americas. Vol. 69, núm. 3: 303-321. Navarro García, Luis. 1959. Intendencias en Indias. Sevilla: Escuela de Estudios Hispanoamericanos.

O'Phelan, Scarlett. 2012. Un siglo de rebeliones anticoloniales: Perú y Bolivia 17001783. Cuzco: Centro de Estudios Regionales Andinos Bartolomé de Las Casas. https://doi.org/10.4000/books.ifea.6367

Ordenanza General formada de orden de su majestad: y mandada imprimir y publicar para el gobierno e instrucción de intendentes, subdelegados y demás empleados de Indias. 1803. Madrid: Imprenta de la Viuda de Ibarra.

Pereyra Chávez, Nelson. 1997. «Un documento sobre Guaman Poma de Ayala existente en el Archivo Departamental de Ayacucho». Histórica. Vol. 21, núm. 2: $261-271$

Ramírez, Susan E. 1996. The World Upside Down. Cross-Cultural Contact and Conflict in Sixteenth Century Peru. Stanford: Stanford University Press.

San Martino de Dromi, Laura. 1999. Constitución indiana de Carlos III. La Real Ordenanza de Intendentes de 1782. Buenos Aires: Ciudad Argentina.

Sarabia Viejo, María Justina. 1986-1989. Francisco de Toledo: disposiciones gubernativas para el Virreinato del Perú. Sevilla: Escuela de Estudios Hispanoamericanos y Consejo Superior de Investigaciones Científicas, 2 vols.

Serulnikov, Sergio. 2003. Subverting Colonial Authority. Challenges to Spanish Rule in Eighteenth Century Southern Andes. Durham y London: Duke University Press. https://doi.org/10.1215/9780822385264

Thomson, Sinclair. 2002. We Alone Rule: Native Andean Politics in the Age of Insurgency. Madison, Wisconsin: The University of Wisconsin Press.

Unanue, José Hipólito. 1793. Guia Política, Eclesiástica y Militar del Virreynato del Perú para el Año de 1793. Lima: Imprenta Real de los Huérfanos.

Vassberg, David E. 1974. «The Tierras Baldias: Community Property and Public Lands in 16th Century Castille». Agricultural History. Vol. 48, núm. 3: 383-401. Zabala, Silvio. 1978-1980. El servicio personal de los indios en el Perú. México, D. F.: El Colegio de México, 3 vols.

Fecha de recepción: 16/VI/2016 Fecha de aceptación: 4/VII/2016 